\title{
FOREIGN STUDENTS' COMMON PROBLEMS IN WRITING CHINESE CHARACTERS
}

\author{
Norlida Razali
}

\begin{abstract}
Chinese characters belong to the ideographic system and are widely different from phonetic writing. ${ }^{1}$ Chinese characters are hard to remember, difficult to write and identify and as such these features have become major obstacles in learning Chinese by foreign students. Therefore, in view of this, it is necessary to research about common problems in writing Chinese characters among foreign students and to provide suggestions to solve common problems. It is expected that this study will provide students a reference to improve writing skills as well as promote interest in learning Chinese. In addition, this research hopes students will be able to correct common errors and learn more effectively. Chinese characters are very unique, with deep cultural connotations, which makes foreigners interested in wanting to learn it, but due to the complex structures of Chinese characters and the diversity, it is extremely difficult for foreign students to learn Chinese characters. This paper starts by discussing common problems encountered by beginners when writing Chinese characters within the context of shape, sound and meaning. Next it highlights the reasons for errors, and puts forward some learning strategies.
\end{abstract}

Keywords: Chinese characters, Pinyin, Homophone and Polyphone Characters

\section{Difficulties in Learning Chinese}

In recent years, along with the development of Chinese economy, the improvement in China's international status, there is an increasing demand globally for learning Chinese language. China has become the "holy land" for many foreign students to learn Chinese. ${ }^{2}$ These students constitute a special group: although they have different cultural background, national language, objectives, but they all strive to make Chinese as their second language learning. ${ }^{3}$ Modern Chinese characters and phonetic writing have huge differences in terms of writing, and if one does not understand the alphabet, the exercise would be futile. ${ }^{4}$ As it is, to write Chinese characters correctly is not easy, and to write beautifully is much harder for foreigners. Even if students achieve oral proficiency at the intermediate stage, one still finds many errors when writing which affects the overall effectiveness of learning Chinese. ${ }^{5}$ The difficulty in learning the language is related to modern Chinese words which uses around 10000 characters, combined with complex

1 Ling Shuai, “From Foreign Students' Writing Errors towards the Role of Phonetic Characters Ideogram in Teaching Chinese Characters", Journal of Chifeng University, Vol. 30, 2009, p 119.

2 Ni Chuanbin, "Research on Foreign Students Attitude toward Chinese Language, Language Education and Research", Journal of Linguistics, Vol.4, 2004, p 56.

3 Ni Chuanbin, p56.

4 Guo Shenglin, "Characteristic of Chinese Character Strokes by Foreign Students Stroke Errors", Journal of School of Chinese Language, Jinan University, Vol.4, 2008, p 64.

5 Guo Shenglin, "Characteristic of Chinese Character Strokes by Foreign Students Stroke Errors", Journal of School of Chinese Language, Jinan University, Vol.4, 2008, p 63. 
structures of words and changes over time in usage and writing. ${ }^{6}$ Chinese characters are very difficult to remember, due to lots of strokes, quantity, similarity, synonym and structure and this make students fear learning Chinese.

Learning Pinyin (official phonetic system for transcribing Mandarin pronunciations of Chinese characters) is easy if learners know the rule of Pinyin letters. The relationship/ combination between the shape, sound, and meaning of Chinese characters makes it difficult to read. For example “类 lei (class), 粒 li (granule), 粮 liang (grain), 粗 cu (coarse)" all contain the character "米”, but the pronunciation and the meaning of these words are different. This uncertainty results in difficulties of learning Chinese characters. Some learners feel that the process of learning Chinese characters is too complicated and this has become the biggest hurdle in learning Chinese among foreign students.

\section{Common Problems in Writing Chinese Characters}

Most foreign students encounter difficulties in writing Chinese characters. This research surveyed 22 foreign students learning Chinese language in China in order to look for reasons of the most common problems faced by foreign students. In so doing, the researcher wanted to suggest ways of improving Chinese language learning. The participants were mainly students from South East Asia learning Chinese in Lanzhou University, China. The survey took place between September and October 2013. A total of 25 questionnaires were sent out but only 22 were returned. The response rate was $88 \%$ and as such the 22 questionnaire were accounted as $100 \%$ of total response, in accordance with survey requirements. Valid questionnaires were coded and analyzed though the EXCEL program. The limitation of the research is related to having participants only from Lanzhou University. Since the number of students are small, the sample collection may be biased.

\section{Methodology}

The main methodology used was a combination of questionnaires and interviews. Survey questions were convenient to access information, but they provided limited answers. Therefore, students were interviewed in order to understand more specifically the difficulties encountered in writing Chinese characters. The interviews also helped to verify answers obtained from survey questions.

\section{Sample Size and characteristic of participants}

Participants who took part in the survey were as follows:

(1) Gender: 3 males, 19 females - the gender ratio of 1:6.

(2) Age: Under the age of 20: 0; 20-30: 21; 30-40: 1; over the age of 40: 0 .

(3) Bachelor degree, 1; Graduates and above, 21, more than $95.45 \%$ had graduate degrees.

(4) The level of Chinese (HSK exam level basis) proficiency: Grade 3-4: 12; 5-6: 9; 7-8: 1. The level of Chinese proficiency obtained at the levels of primary, intermediate,

6 Shao Caixia, "Cultural Implications of Chinese Character Education [J]", Modern Education of Primary and Secondary Schools, Vol.12, 2010, p 23. 
advanced were $54.55 \%, 40.90 \%$ and $4.55 \%$ respectively. Twelve questions were put forward to participants.

\section{Questions}

(1) Do you think Chinese characters are difficult to learn?

\begin{tabular}{|l|c|c|}
\hline Options & Number & Percentage (\%) \\
\hline Too difficult, cannot learn & 4 & 18.18 \\
\hline Difficult, but can be learnt & 17 & 77.27 \\
\hline Not difficult, easy to learnt & 1 & 4.54 \\
\hline
\end{tabular}

$77.27 \%$ students thought that although Chinese characters were difficult but they could still be learnt. The result shows that students were positive despite difficulties encountered.

(2) What do you think is the most difficult part in Chinese language?

\begin{tabular}{|c|c|c|}
\hline Options & Number & Percentage (\%) \\
\hline Grammar & 6 & 27.27 \\
\hline Spell (Pinyin) & 3 & 13.64 \\
\hline Chinese character & 9 & 40.90 \\
\hline Vocabulary & 5 & 22.73 \\
\hline Others & 0 & 0 \\
\hline
\end{tabular}

Nine students found it difficult to learn Chinese characters, accounting for $40.90 \%$, followed by eleven students finding it difficult to learn Chinese grammar and vocabulary, accounting for $27.27 \%$ and $22.72 \%$ respectively. The results show that leaning Chinese characters as the most difficult part in the overall learning process and also it is the root cause for others difficulties.

(3) What do you think is the basic composition unit of a Chinese character?

\begin{tabular}{|l|c|c|}
\hline Options & Number & Percentage(\%) \\
\hline Strokes & 7 & 31.82 \\
\hline Component & 7 & 31.82 \\
\hline Chinese characters & 8 & 36.36 \\
\hline
\end{tabular}

The data shows that students lack basic knowledge of Chinese characters. While 31.82\% were correct in answering the basic unit of a Chinese character is the stroke, more than $67 \%$ answered incorrectly. 
(4) How do you learn to write Chinese characters?

\begin{tabular}{|l|c|c|}
\hline Options & Number & Percentage $(\%)$ \\
\hline First learn strokes, then learn strokes order & 10 & 45.45 \\
\hline Only pay attention to learn the component & 11 & 50.00 \\
\hline Only pay attention to learn strokes order & 1 & 4.55 \\
\hline
\end{tabular}

Results show that students are not aware of the importance of learning to write according to the right sequence. Writing characters in the correct order is essential for the character to look correct. Only $4.55 \%$ learn the correct strokes order.

(5) Do you know what is the function of Chinese character components?

\begin{tabular}{|l|c|c|}
\hline Options & Number & Percentage (\%) \\
\hline $\begin{array}{l}\text { Remember the components, } \\
\text { so can write the character }\end{array}$ & 5 & 22.73 \\
\hline $\begin{array}{l}\text { Know the components, } \\
\text { so can know the meaning of the character }\end{array}$ & 13 & 59.09 \\
\hline Don't know & 4 & 18.18 \\
\hline
\end{tabular}

Character components typically indicate the meaning and sound of the whole character. While more than $50 \%$ of the students understand that components help to indicate the meaning of the character, more than $18 \%$ are unaware of this fact.

(6) Do you know Chinese character formations?

\begin{tabular}{|l|c|c|}
\hline Options & Number & Percentage (\%) \\
\hline Know & 14 & 63.64 \\
\hline Don't know & 8 & 36.36 \\
\hline
\end{tabular}

There are four ways of formation for Chinese characters, namely pictographs, indicatives, ideates and harmonics. Results of the survey indicate that $63 \%$ of the students seem to know how characters are formed.

(7) Do you know Chinese characters structure? (left, right, up, down, and others)

\begin{tabular}{|l|c|c|}
\hline Options & Number & Percentage (\%) \\
\hline All know & 6 & 27.27 \\
\hline Some know & 13 & 59.09 \\
\hline No at all & 3 & 13.64 \\
\hline
\end{tabular}

Overall, students seem to know the structure of Chinese characters though not comprehensively. Only $27.27 \%$ of students know the structure of Chinese characters. 
(8) What difficulties do you encounter when learning Chinese characters? (multiple choice)

\begin{tabular}{|l|c|c|}
\hline Options & Number & Percentage (\%) \\
\hline $\begin{array}{l}\text { See the character, do not know how to } \\
\text { read / pronounce }\end{array}$ & 12 & 54.55 \\
\hline Write strokes wrongly & 2 & 9.09 \\
\hline Unclear strokes order of the characters & 8 & 36.36 \\
\hline Always confused with the component & 3 & 13.63 \\
\hline $\begin{array}{l}\text { Always confused with the homophone and } \\
\text { polyphone characters }\end{array}$ & 9 & 40.91 \\
\hline Difficult to distinguish characters with similar forms & 4 & 18.18 \\
\hline Others & 0 & 0 \\
\hline
\end{tabular}

The above shows clearly difficulties faced by foreigners in learning the Chinese language. More than $54 \%$ cannot read or pronounce a character and $40 \%$ of the students are confused with the homophone and polyphone characters. Further, more than $35 \%$ are unsure of the sequence of the strokes.

(9) What common mistake do you always make when writing Chinese characters? (multiple choice)

\begin{tabular}{|l|c|c|}
\hline Options & Number & Percentage (\%) \\
\hline Confused with the strokes & 5 & 22.73 \\
\hline Confused with the component & 8 & 36.36 \\
\hline Confused with the structure & 4 & 18.18 \\
\hline Confused with the similar homophone characters & 8 & 36.36 \\
\hline Confused with the similar shape characters & 7 & 31.82 \\
\hline
\end{tabular}

The most common mistake made when writing Chinese characters is related to the confusion of the component of a character or similarity of homophone characters. This shows students find it hard to differentiate similar shapes, sounds and components of Chinese characters.

(10) What method do you use to remember Chinese characters? (multiple choice)

\begin{tabular}{|l|c|c|}
\hline Options & Number & Percentage (\%) \\
\hline Constantly copying Chinese characters & 8 & 36.36 \\
\hline Constantly looking and reading Chinese characters & 15 & 68.18 \\
\hline Linking characters in the word with related story & 8 & 36.36 \\
\hline Others & 0 & 0 \\
\hline
\end{tabular}

$68.18 \%$ of students use the traditional method of looking and reading Chinese characters. This is followed by $36 \%$ of students copy writing Chinese characters and relating 
characters certain stories. These results show that students are traditional and do not use other innovative methods to learn Chinese characters.

(11) What kind of teaching method do you think is most effective? (multiple choice)

\begin{tabular}{|l|c|c|}
\hline Options & Number & Percentage (\%) \\
\hline $\begin{array}{l}\text { Demonstration of strokes order of Chinese characters } \\
\text { on the whiteboard }\end{array}$ & 10 & 45.45 \\
\hline $\begin{array}{l}\text { Using multimedia to teach } \\
\text { Chinese characters }\end{array}$ & 9 & 22.73 \\
\hline $\begin{array}{l}\text { Telling the origins or related story of the Chinese } \\
\text { characters formation }\end{array}$ & 2 & 40.91 \\
\hline $\begin{array}{l}\text { Create combinations games of Chinese characters } \\
\text { component }\end{array}$ & 8 & 36.09 \\
\hline $\begin{array}{l}\text { Use mnemonic method to remember similar sounds and } \\
\text { shapes of characters }\end{array}$ & 2 & 9.09 \\
\hline Others & 56 \\
\hline
\end{tabular}

The table indicates that teachers rely on demonstration Chinese character strokes order on the whiteboard as the most effective way to learn. This is followed by telling stories of Chinese characters formation and using mnemonic methods to remember similar sounds and similar shapes characters. The results show that using multimedia tools and games in the classroom is quite unpopular.

(12) What do you think is the most effective method to learn Chinese characters? (multiple choice)

\begin{tabular}{|l|c|c|}
\hline Options & Number & Percentage (\%) \\
\hline Pay attention and focus in the classroom & 9 & 40.91 \\
\hline Set up learning plan after class, keep up writing practice & 4 & 18.18 \\
\hline $\begin{array}{l}\text { Interact more with teachers and classmates, } \\
\text { Encouraging each other }\end{array}$ & 7 & 31.82 \\
\hline $\begin{array}{l}\text { Learn and understand more about Chinese } \\
\text { history and culture }\end{array}$ & 4 & 9.09 \\
\hline $\begin{array}{l}\text { Choose interesting extracurricular activities } \\
\text { related to Chinese language }\end{array}$ & 6 & 27.27 \\
\hline Watch Chinese television programs & 0 & 0 \\
\hline Others & & \\
\hline
\end{tabular}

Students think that the most effective method to learn Chinese characters is to rely on the teacher and interact more with teachers and classmates. Interestingly more than $20 \%$ prefer watching Chinese programs on television. It is interesting that students rarely do independent learning because they rely too much on their teachers. Finally, although the formation of Chinese characters has a very long history, students are not 
very interested in understanding Chinese history and culture in order to learn Chinese characters.

\section{Analysis}

Overall, students lack basic knowledge of writing Chinese characters writing. First of all, they lack solid skills in knowing the stroke order. During the interviews and observation period, even students at the intermediate and advanced stages, lack skills in mastering the stroke order and they are still unclear about the relationship between the strokes. The most prominent problem is understanding the number of strokes needed in writing a particular character. Second, students have very little knowledge of Chinese characters' components. One may argue that this is the case due to problems existing in students' memory and cognition, especially inadequate understanding of ideographic elements.

\section{Reasons for Common Problems among Foreign Students}

Chinese character is a record of symbols. Chinese characters have more than 80000 words. Modern Chinese word usage is around 10000 words, which includes 7000 words in general use, and 3500 words in common use. ${ }^{7}$ Chinese characters are difficult to recognize and hard to write. Lots of practice is needed when learning to write. Students need to repeat writing a single character numerous times, this makes the learning process very boring and exhausting. ${ }^{8}$

Chinese characters are constructed by sound, shape, and meaning ${ }^{9}$ that make the Chinese language expression very incisive. Chinese characters is arranged through strokes, components, structure and composition. One Chinese character only represents one syllable. The existence of large number of multi-tone, polyphones, and homophones has led to foreign students complaining and even losing interest in learning Chinese.

Chinese characters are mysterious. Students with non-Chinese cultural background feel very strange with shape-meaning characters as they are accustomed with phonetic writing sound. The structures seem complex and rules regulated and learning through memory to remember words is very tedious for foreigners. ${ }^{10}$

Having a different mother tongue and differences each country's language results in students producing mistakes in writing Chinese characters. ${ }^{11}$ Therefore due to the lack of understanding of Chinese characters, students are unable to find the connection between sound and shape as their brain are unable to process image of a word. As a result, writing of Chinese characters with its strokes order leads to internal confusion. Students tend to make several common writing errors.

\footnotetext{
Shao Caixia, $\mathrm{p} 23$.

Shao Caixia, p24.

Shao Caixia, p23.

10 Du Han, "Research on Survey and Countermeasures of Writing Errors of Chinese-characters: Aiming at International Students without Cultural Background of Chinese Characters", Unpublished Master's Thesis, Jilin University, 2011, p 14-15.

11 Du Han, p 23.
} 


\section{(A) Shape Mistakes ${ }^{12}$}

Writing errors due to shape mistakes includes two types, first is the pen-shaped inaccuracy and the second is the pen-shaped mixed.

1: $\quad$ Pen-shaped inaccuracy

(1) Chinese characters are written according to strokes, this requires smooth vertical and horizontal lines, but students affected by the impact of national language, often will write the strokes same as when they write the alphabetic based words. The most typical example is writing the "口" into " $\mathrm{O}$ ", " 七" into

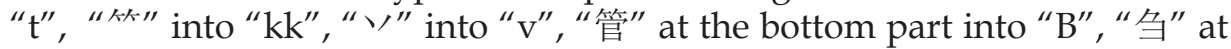
the bottom part into" $E$ " and "邓" at the right part into" $\beta$ ".

(2) There are also many errors in strokes. Most foreign students because of their mother tongue language habits, will distort the strokes such as " " into ", " and " $\mathrm{J}$ " into " $/$ ".

\section{2: $\quad$ Pen-shaped (strokes) mistake}

The shape of modern strokes in Chinese characters is varied. Different shapes of strokes can compose many different characters. Because there are many similarities in Chinese characters based words, many foreign students write the wrong stroke order because of confusion and not knowing the sequence of the strokes. ${ }^{13}$ Chinese characters with more or less strokes will create different Chinese words and meanings which confuses many foreign students. The simplest example is " 目"(eye), with one less vertical stroke will become “日”(day), hence the meaning changes completely.

(1) There are different Chinese characters with similar stroke shape that causes confusion among foreign students. Although the shape changes between the similar characters in terms of meaning, there is no relation, however, due to form similarity and closeness, students tend to switch the characters during the writing process. ${ }^{14}$

\section{For example,}

The dot stroke, such as:

王 and 玉; 庆 and 厌; 治 and 冶; 设 and 没; 准 and 淮

The horizontal stroke, such as:

住 and 住; 巫 and 坐; 末 and 未; 休 and 体; 酒 and 酒

The vertical stroke, such as:

候 and 侯; 甲 and 申; 田 and 由; 早 and 早; 巨 and 臣

The left-falling stroke, such as:

矢 and 失; 午 and 牛; 石 and 右; 刀 and 力; 开 and 井

12 Yu Xiaowei, "The Origins of Foreign Students Chinese characters Errors", Journal of Xiangfan University Vocational and Technical Collage, Vol.6, 2010, p 76.

13 Zhang Yongyun, " Analysis of International Students' Writing Errors and Teaching Strategies", Unpublished Master's Thesis, Lanzhou University, 2011, p 6.

14 Ling Shuai, p119. 
All these errors creates a different Chinese character. They need careful attention and observation.

(2) Then there are some others commonly confusing Chinese character words that often lead students to add more or less strokes causing further writing errors.

Students might add more or less strokes at the top of a character:

白and百; 户 and户; 史and吏; 万and方; 木and禾; 兄and兑; 之and乏; 内 and 丙; 业 and 亚; 义 and 义; 火 and 灭; 厂 and 广; 夫 and 失; 杳 and 香; 天 and 矢; 夕 and 歹; 再 and 再; 住 and 往; 无 and 尤; 未 and 朱; 目 and 自

Adding more or less stroke at the bottom part of a character:

代and伐; 尤and龙; 折and拆; 乘and乘; 全and金; 乃and及; 氏and 氏; 免and 兔; 木 and 本; 从 and 丛; 目 and 且; 斤 and 斥; 爪 and 瓜; 西 and 西; 今 and 令; 乒 and 兵; 直 and 真; 占 and 点; 日 and 旦; 仟 and 任; 亨 and 享

Adding more or less stroke at the middle part of a character:

勺 and 匀; 九 and 丸; 也 and 也; 庆 and 床; 哀 and 衷; 又 and 叉; 卯 and 卵; 几 and 凡; 心 and 必; 丁 and 于; 勿 and 勿; 竞 and 竟; 戊 and 戊; 廿 and 甘; 川 and 州; 予 and 矛; 乌 and 鸟; 戎 and 戒; 要 and 要; 日 and 目; 问 and 间

Modern Chinese characters have a lot of characters with similar shapes, the difference between each word is not that huge. Sometimes the difference is only in the length of the stroke and sometimes the difference is based on the direction of the stroke. Besides, there are many similar characters, the difference is often only in one or two strokes, such in “兴” and “光". ${ }^{15}$ In addition, some others common Chinese character words have very high level of similarities and are confusing for foreign students such as:

农 and 衣; 干 and 于; 人 and 入; 土 and 士; 已 and 已; 戌 and 戌; 贝 and 见; 录 and 隶; 崇 and 崇; 亩 and 宙; 亦 and 亦; 实 and 买; 冢 and 家; 开 and 灭; 茶 and 茶; 李 and 季; 余 and 余; 毒 and 毒; 市 and 市; 浆 and 桨; 爰 and 爱;

政 and 致; 选 and 送; 阵 and 陈; 究 and 穷; 俊 and 梭; 枚 and 牧; 悦 and 说;

撤 and 撒; 泰 and 秦; 施 and 旋; 伏 and 优; 或 and 咸; 虚 and 虑; 衰 and 衷;

索 and 素; 赛 and 塞; 持 and 特; 矢 and 失; 币 and 币; 故 and 敌; 复 and 夏;

害 and 善; 稳 and 隐; 辛 and 幸; 环 and 坏; 恋 and 恶; 际 and 标; 官 and 宫; 博 and 傅; 佳 and 挂; 译 and 释; 垓 and 核; 寄 and 奇; 祥 and 样; 监 and 临;

15 Guo Shenglin, " Characteristic of Chinese Character Strokes with Foreign Students Chinese Characters Stroke Errors", 2008, p64. 
悬 and 县; 舟 and 丹; 第 and 第; 尖 and 尘; 览 and 贤; 猪 and 猎; 谐 and 楷;

雾 and 零; 廷 and 延; 似 and 拟; 哲 and 暂; 卷 and 券; 饲 and 词; 祭 and 察;

感 and 惑; 坚 and 坚; 怡 and 恰; 岗 and 岗; 粗 and 租; 软 and 钦; 刊 and 刑; 弊 and 憋; 阮 and 院; 败 and 贩; 雀 and 省; 皆 and 旨; 透 and 诱; 杳 and 沓;

幕 and 墓; 贪 and 贫; 袁 and 哀; 堂 and 棠; 屑 and 肩; 恕 and 怒; 恳 and 垦; 裁 and 载; 毕 and 华; 贷 and 货; 浩 and 活; 窒 and 室; 康 and 庚; 愉 and 偷;

匀 and 习; 天 and 天; 祛 and 怯; 梨 and 犁; 痁 and 店; 蓝 and 篮; 多 and 炎;

宴 and 冥; 拔 and 拨; 推 and 堆; 晋 and 普; 库 and 厍; 划 and 划; 科 and 料;

貘 and 貌; 凤 and 夙; 曲 and 冊; 锒 and 银; 蜜 and 密; 昜 and 易; 船 and 般; 襄 and 囊; 狠 and 狼; 街 and 衔; 寇 and 冠; 待 and 侍; 棒 and 捧; 刺 and 刺.

\section{(B) Components Confusion}

Components generally include single character component or compound character components. Many Chinese characters are composed of left-right components, but students are not clear about this rule. They tend to split one word into two separate characters, like “跳” into 足 and 兆. Due to a lot of Chinese character structure combining between single characters and components, students find it obscure and difficult to identify which leads to writing errors. The confusion of components are mainly reflected in the following aspects:

(1) Adding of components ${ }^{16}$

Commonly added components in Chinese characters such as:

桌椅 into (棹) 椅; 及格 into (极) 格; 告诉 into（诰）诉; 争论 into (诤) 论; 赞扬 into（攒）扬 and others.

(2) Reducing components ${ }^{17}$

Commonly reduced components in Chinese characters include:

城堡 into 城（保）; 城市 into（成）市; 聪明 into（总）明; 根源 into 根 ( 原) : 小姐 into 小 (且) and others.

This kind of situation appears because the sound or tone of words are difficult to identify, making it easy for foreign students to make mistakes in writing.

\footnotetext{
16 Ling Shuai, p119.

17 Ling Shuai, p119.
} 
Other examples for commonly reduced components of Chinese characters include: 冻 into 东; 测 into 则; 证 into 正; 源 into 原; 远 into 元; 喝 into 曷; 绯 into 非; 转 into 专; 帽 into 冒; 除 into 余; 神 into 申; 楸 into 秋; 理 into 里; 锻 into 段;

张 into 长; 站 into 占; 烤 into 考; 懒 into 赖; 饱 into 包; 睡 into 垂; 艇 into 廷.

Reducing components is more common than adding components to a character because students normally rush or get confused when they are composing a character. Students usually imitate, and as such during the process of imitation, all sorts of mistakes appear. In addition, students do not practice enough in writing correctly and teachers do not give effective guidance when students learn how to write the stroke order. ${ }^{18}$

3. Component transformation / replacement of position ${ }^{19}$

Compound words in Chinese characters are structured, including upper and lower structure, right and left structure, and the surrounding structure as well. These varieties makes students to write incorrectly, like the examples below:

Left and right position example:

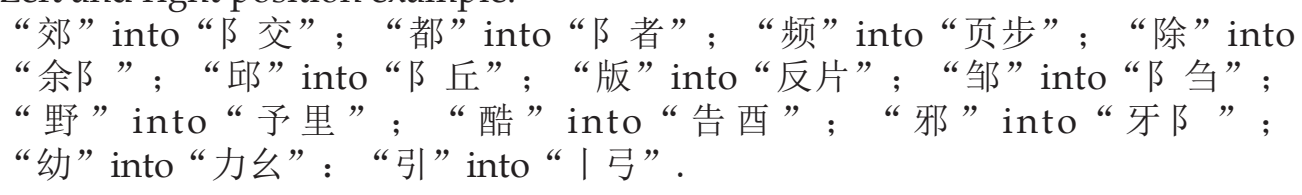

Up and down position example:

杲 into 杳; 旮 into 晃; 杏 into 呆

The changing or transformation position occurs mainly because components in Chinese characters are not in a static position. Such uncertainty results in students making errors. Sometimes, students write characters too far apart or separately.

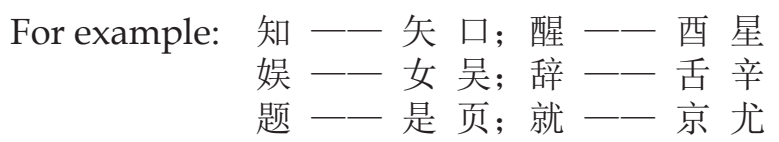

\section{(C) Sound (tone) Mistakes ${ }^{20}$}

There are four tones in the Chinese language. The symbols are $\left(^{-}\right),\left(^{\prime}\right)$, $\left({ }^{`}\right)$ and $\left({ }^{\prime}\right)$. These tones can be divided into three categories:

18 Wang Shuai, Foreign Students Chinese Writing Common Problem and Teaching Strategies, p 251.

19 Zhang Yongyun, " Analysis of International Students' Writing Errors and Teaching Strategies", , 2011, p 6.

20 Yu Xiaowei, " The Origins of Foreign Students Chinese characters Errors", Journal of Xiangfan University Vocational and Technical Collage, Vol.6, 2010, p 76. 
i) Same sounds such as:

$$
\text { “朵” (duo) and “躲” (duo); “非” (fei) and “菲” (fei). }
$$

ii) Similar sounds such as:

$$
\text { “丁” (ding) and “汀” (ting); “广” (guang) and “旷” (kuang) }
$$

iii) Completely different sounds such as:

$$
\text { “又”(you) and “汉” (han); “是”(shi) and “提”(ti) }
$$

Because of similar tone pronunciation of characters, the occurrence of errors is huge. Chinese characters have a large number of similar characters, homophones, coupled with phonetics. Sometimes characters do not necessarily reflect the sound of the shape, so students find it difficult to accurately write Chinese characters. As a result most students write in accordance to known sounds of Chinese character.

Another reason is the proliferation of computers and when reading materials are in Chinese. When one is looking for a word, the input method does not require one to enter the full pinyin word which is not conducive for students to learn and improve their Chinese writing abilities. Sound or tone pronunciation errors generally include the following categories:

1. Same sounds / tone ${ }^{21}$

Example: 秀 (绣) 花 xiù (xiù) huā; 夜霄（宵）yè xiāo (xiāo); 模形（型） mó xíng (xíng); 木厢（箱） mù xiāng (xiāng); 萧（波）酒 xiāo (xiāo) să; 须 (需) 要 $x \bar{u}(x \bar{u})$ yào; 疏（蔬）菜 shū (shū) cài。

2. Similar sounds / tone and character ${ }^{22}$

Example: 眼睛（镜）yănjīng (jìng); 一副（幅）画 yī fù (fú) huà; 注（主） 意zhù (zhǔ) yì; 汉字(子) hànzì (zi); 弹（单）身 dàn (dān) shēn；安（按） 照 ān (àn) zhào; 不能自己（已） bùnéng zìj (y̌̃); 一只（支）笔 yī zhǐ (zhī) bǐ ; 年令 (龄) nián lìng (líng); 时侯（候） shí hóu (hou).

3. Similar sounds but completely different character and meaning

Example:

统计 “tǒngjì" (statistic) and 通缉 “tōngjī" (wanted);

边际 “biānjì" (boundary) and 编辑 “biānjí" (edit);

整齐 “zhěngqí” (neat) and 蒸汽 “zhēngqi”"(steam).

其实 “qíshí”(actually) and 启事 “qǐshi” (notice);

提醒 “tíxǐng” (remind) and 体型 “tǐxíng” (body);

生气 “shēngqì"(angry) and 升起 “shēngqǔ ”"(rise);

${ }_{21}$ Zhang Yongyun, ” Analysis of International Students' Writing Errors and Teaching Strategies", Unpublished Master's Thesis, Lanzhou University, 2011, p 6.

22 Ibid., p6. 


\section{(D) Mistaken Meanings}

1: $\quad$ The Analogy components ${ }^{23}$

Students in the process of writing Chinese characters often will write parts according to their own understanding. They write Chinese characters which have similar meanings when they are unable to write accurately. The main reason for this is similar or close meanings of the component. Some examples of this include: 口”, “i (言) ”(related with mouth) example: 说(speak), 讲(speech), 唱(sing), 喊 (shout), 喝(drink); “未”(related with hand) example: 打(hit), 推(push), 拉(pull), 捏 (pinch), 按(press); “シ ”(related with water) example: 洗(wash), 河(river),汤(soup), 流(flow), 渴(thirst) and other components with similar meanings. However, since Chinese characters have many components, some of the meanings meaning may not be related, such as: “马”(horse) and“骗(cheat), 验(test), 骄(proud)”, unrelated to horse; “车”(car) and"轻(light), 软(soft), 斩(cut)", unrelated to car and others. Because of this students once again get confused and find it difficult to grasp the right method of writing characters accurately.

Others component of Chinese characters that are too confusing for foreign students

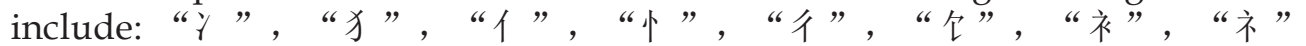

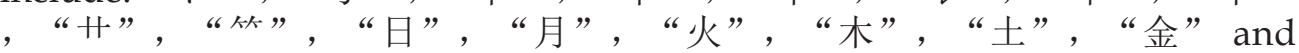
others. This becomes a problem for students since they are unsure of the position of the component part in the character. The simplest example is “包” - 饱(full), 抱(hold), 跑(run), 泡(bubble), 炮(gun), 袍(robe), 咆(roar), 狍(roe), 胞(cell) , 苞(bud), and 枹 (oaklet). If wrongly put, the word will differ with different meanings. Some examples include:

“青” 一 请, 清, 情, 凊, 啨, 晴, 箐, 菁, 腈, 埥, 錆, 掅

“非” — 诽, 渄, 悱, 排, 啡, 徘, 腓, 菲, 裶, 婔, 俳, 棑

“同” — 烔, 筒, 桐, 侗, 洞, 恫, 胴, 挏, 狪, 垌, 晍, 銅

“扁”- - 偏, 篇, 谝, 楄, 徧, 揙, 煸, 惼, 褊, 猵, 骗, 媥

“曼”- - 慢, 漫, 蔓, 谩, 熳, 僈, 摱, 槾, 獌, 嫚, 馒, 墁

2. Other than that, in the Chinese language, there are also many words with similar meanings which leads to mistakes when writing Chinese characters. These include: “小”(small) and“少 (less)”; “讲”(speech) and“说” (speak); “查”(check) and “察”(observe); “生”(born) and “产”(produce).

3. Connection of meanings between words

Another reason for mistakes is related to the misuse of connections between words which have similar meanings. Students struggle to distinguish and identify the differences. The words in this category include: “晌午” (noon) written as “上 午”(forenoon); “互相” (each other) written as “相互” (together); “海上”(seaborne) written as “上海” (at sea) and “现实”(real) written as “实现” (realize).

The above is the summary of the common mistakes made by foreign students in the process of learning the Chinese language, especially in writing Chinese

23 p Ling Shuai, pp 118-120. 
characters. In view of the above errors, the following will discuss some strategies in overcoming common mistakes.

\section{Strategies for Improvement}

Foreign students face problems when writing Chinese character strokes, components, and structure. ${ }^{24}$

\section{(A) Strategies for Studying Chinese Character Strokes}

Foreign students are easily confused by the fact that there are so many similar characters in writing Chinese. Therefore, it is very important for students to have basic skills on how to draw strokes correctly from the very beginning of the learning process. There are eight basic strokes - horizontal stroke (一), vertical stroke ( I ), dot stroke ( ' ), left-falling stroke ( ) ), right-falling stroke ( $\backslash$ ), folding stroke $(\rightarrow)$, hook stroke and upwards stroke.

Horizontal and vertical strokes seem to be used the most. ${ }^{25}$ Zhang Jingxian's statistic shows that Chinese characters are composed of $27.68 \%$ horizontal strokes, $17.60 \%$ vertical strokes, $15.95 \%$ of right-falling strokes hold and $13.62 \%$ of dot strokes. All these strokes do not look too difficult, but compounding strokes in the exact order accurately is not very easy to learn. Forming strokes is the most basic element of studying Chinese language. In order to write accurately, attention should be paid to learning strokes-writing from the very beginning.

1: One needs to pay attention in class. When a teacher is explaining the characters strokes, stroke order and basic knowledge of Chinese characters, one should listen carefully. Constant practice and imitating what the teacher does helps a lot. Students should pay more attention to characters that are relatively difficult to write. Memorizing characters is often condemned as a method but it is the fastest way to improve language skills and characters. In order to write Chinese characters accurately, there is no other way than practicing and more memorizing.

2: $\quad$ Emphasize on summarizing

Each time after writing strokes, summarization is an excellence way to memorize characters through classification characters into "similar characters" and "difficult to write characters. Strokes can be classified into several groups -"vertical rising strokes” (坚提) which are generally at the left side like in “长”, “很”, “低” the "vertical hook strokes" (坚钩) are usually at the right side or in the middle like in “于”, “身”, “团”,“小”,“刘”，for “horizontal hook strokes”（横钩）, one always can see it above like in “军”, “罕”, “买,"vertical curved hook strokes” (坚弯钩) generally appear at the final stroke in every character like“已”, “也”,"电”. By doing these classifications, it will be easier for students to remember and memorize strokes, as well have a solid foundation in accurately writing Chinese characters.

3: Characters with similar strokes should be memorized. For example: “今” and “令”; “已”and“已”; “千”and“干”; “未”and“末”; “白”and“百”. Because these Chinese characters look very similar to each other, just remembering the character

24 Zhang Yongyun, " Analysis of International Students' Writing Errors and Teaching Strategies", 2011, p14-26.

25 Zhang Jingxian, Liang Yanmin, and Zhao Lei, Chinese Character Tutorial [M], Beijing Language and Culture University Press, 2004, p 160-173. 
will not allow one to distinguish words. However, if one uses the character inside a certain word, one can easily find the differences in any context. This method also can help students to understand each character better. For example: “今天”(today) and “命令”(command); “自己”( oneself) and “已经”(already); “千万”(must) and “干活”(work); “未来”(future) and“末日”(end/doomsday); “白天”(daytime) and “百万”(million)..

\section{(B) Strategies for Studying Chinese Character Components}

Component is a very important structure in modern Chinese writing. The vast majority of Chinese characters are composed of compound character words. The component plays a core position in learning Chinese characters. Students should pay more attention to studying the components.

1: To analysis the components, try to jointly remember the pronunciation, shape and meaning of the word, especially the phonetic and the whole word pronunciation of the same or similar Chinese characters. In so doing your memory will classify these words more easily. As an example: “情”(feeling) vertical stroke (小 ) “心”(heart) represent the meaning, “青" represents the sound "qing" when the combination of this two different component parts take place, the vertical stroke “心” indicates the heart, together with “青” becomes “情”, which means a combination of emotions, feelings, and the mood to express people's inner feelings. In other words, the contact and connection will enable us to easily understand the impression of any Chinese character.

2: Students have to master basic components, and then from the usually used characters to not commonly used characters, simple characters to complex characters and the regular pattern to classify characters. For instance, if one already knows a lateral character “心”and “青”, the character “情” becomes easier to learn, and students do not feel at a loss when reading the character. This summing-up is a process that cannot be rushed as students have to learn step by step as it takes time to understand.

3: Students need to be good at linking or connecting the ideas. For example, “森” is composed by “木”， which“木 represent a tree, when three “木” are put together, it means a lot of trees, a lot of trees indicates the forest “森林”. In the end this process allows one to remember the character and the meaning better. Another example pertains to relationship - a man “男子” needs a woman “女人” to accompany which is indicated in “好” (good). With this humorous interpretative method, one can break through the traditional teaching mode, enable students to learn faster and remember better. Linking concepts is a very efficient method to study the Chinese language.

\section{(C) Strategies for Studying Structure}

Majority of Chinese characters are compound words, which means there are components, and at the same time also structure of Chinese characters. Some component position is not static or not always in a regular position and this leads to students easily making mistakes in terms of the character's structure when writing. 
1: In order to avoid this, students must summarize the positional relationship of the various components of Chinese characters, such as: “シ、タ、そ、个、イ、イ、

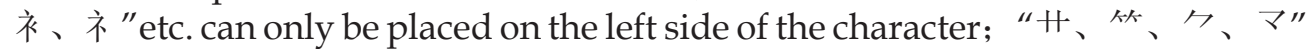
etc. can only be placed on the upper part of a character; “皿、 ...." etc. can only be placed at the lower part of the character; " $\square$ " is usually placed outside the character. These are very regular position for this kind of components. Students can easily remember these common positions when determining the structure of Chinese characters.

2: Students must also analyze the structure, learn to split and to link ideas. For example, “孬” has a top-and-bottom structure, so one can split “孬” into two parts, “不” (not) and “好”(good), which indicates that the two words together is called “丕” which means"bad. Another example is “休”, this character can be split into: (个 )“人”(a person) and “木” (a tree), the combination of these two characters indicates" a person who leans on a tree" or resting (休).

\section{Conclusion}

The common problems described above in writing Chinese characters are not the only problems that foreign students face. At times, teachers do not guide enough, in most cases Chinese language teaching methods are not perfect and there is a lack of independent teaching materials. Therefore, writing Chinese characters accurately not only depends on students' efforts but also school management and teachers. If all parties work hand in hand, foreign students will automatically improve their language skills in reading, writing and composing. 